\title{
DETERMINAÇĀO QUANTITATIVA DE GRUPOS DE BACTÉRIAS EM SUCOS DE LARANJA AO NATURAL *
}

Dircell do Nascimento **

Sirdeia M. P. Furlanetto

\begin{abstract}
¿ASClMENTO. D. do \& FLRLANETTO. S.M.P. Determinagão quantitativa de grupos de ractérias em sucos des laranja al natural. Res. Saúde púhI. S. Paulu, 15:221-35. 1981
\end{abstract}

RESUMO: Foi realizada investigação com a finaliảade de se conhecer a microbiota aeróbla do suco de laranja ao natural oferecido ao consumo público, através das contagens de bactérias mesófilas e ácido-produtoras, e da determinação do número mais provável (NMP) de bactérias coliformes totais e fecais e de estroptococos fecais.

UNITERMOS: Alimentos, microbiologia. Suco de frutas naturais. Suco de laranja.

\section{INTRODUCÃO}

0) estabelecimento de padries de qualidade para os alimentos e de especificaçoes yuanto aos limites de tolerància, relativos a microrganismos patogênicos, dependem do conluecimento prério da microbiota desses produtos bem como da influência que fatores resionais exercem sobre o numero e os tipos de microrganismos encontrados.

No Brasil, no que se refere a sucus de laranja ao natural, tanto na área de Saúde Pública como na indústria, não existem informaçoes que permitam o estabelecimento de parametros yue se ajustem a nossa realidade e às nossas necessidades. Dada a eridência deste problema, os padroes micro- hiológicos adotados l11:2.:1 para sucos de flutas sāo tentativos, devendo-se frisar que dependendo de estudos sobre a microbiologia desses produtos, tais padrões poderão ser alterados.

Assim sendo, tendo em vista a necessidade de se oferecer subsidios para o estabelecimento de padroes concordes com as condições de nosso pais, resolvemos verificar a presença de microrganismos deteriorantes assim como daqueles considerados como indicadores de poluição fecal em amostras de suco de larania servido ao natural.

* Extraido da tese apresentada à Facullade de Ciências Farmacêticas da Universidade de São Paulo, em 1977. subordinada ao título "Flora nicrobiana de sucos de laranja ao natural" para a obtenção do grau de Mestre em Ciências dos Alinentos

* Do Departamento de Tecnologia Química e de Alimentos do Centro de Tecnologia da Universidade Federal da Paraíba - Cidade Universitária - 58000 - João Pessoa, PB Brasil.

*** Do Departamento de Microbiolosia + Inpulologia do Instituto de Cièncias Biomédicas da $[$ SP - Setor Saude Pública - Ar. Dr. Arialdo, 715 - 01255 -- São Paulo. SP Erasil. 
NASCIMENTO, D. do \& FURLANETTO. S.M.P. Determinação quantitativa de grupos de bactérias em sucos de laranja ao natural. Rev. Sanide públ., S. Paulo, 15:221-35, 1981.

\section{MATERIAL E METODOS}

As amostras de suco de laranja utilizadas neste trabalho foram colhidas em dez lanchonetes e restaurantes da Cidade Universitária "Armando de Salles Oliveira", da Universidade de São Paulo. De cada estabelecimento foram obtidas dez amostras, perfazendo 0 total de cem.

Como as nossas condições não permitiam o exame simultâneo de todas as amostras, numa única amostragem, esta foi feita parcialmente, coletando-se duas ou três amostras por vez, uma em cada lugar diferente, até completar dez amostras para cada estabelecimento.

Mais dez amostras de suco foram colhidas em domicilios, nas condições normais de higiene caseira, na tentativa de se obter um parâmetro de comparação para a análise das amostras estudadas.

O suco foi coletado em frascos estéreis de $450 \mathrm{ml}$, fechados com tampas também estéreis e acondicionados em caixa de material isotérmico, com gelo, e transportados para o laboratório. A quantidade de suco coletada foi da ordem de $150-200 \mathrm{ml}$. O tempo decorrido entre a coleta das amostras e o início do seu exame microbiológico, em nenhum caso excedeu a $45 \mathrm{~min}$.

No laboratório, o suco foi homogeneizado, após o que foi diluido de $10^{-1}$ à $10^{-6}$ usando-se como diluente água tamponada fosfatada estéril.

O suco de laranja ao natural, apesar de apresentar pH 3,4 a 4,5 , não foi neutralizado antes da análise microbiológica, pois um "teste piloto", realizado com vinte amostras, indicou não haver diferenças quando comparamos os resultados do suco neutralizado com os do não neutralizado. A neutralização foi feita com solução aquosa de hidróxido de sódio $1 \mathrm{~N}$.

Contagem padrão de bactérias mesófilas em placas (segundo Thatcher e Clark ${ }^{34}$, 1973), depositaram-se porções de $1 \mathrm{ml}$ das diluições em placas de Petri estéreis, às quais eram adicionadas $15 \mathrm{ml}$ de ágar glicose - extrato de levedo - triptona fundido e resfriado a $43^{\circ} \mathrm{C}$. Após homogeneização e solidificação do ágar, as placas eram incubadas a $35^{\circ} \mathrm{C}$ por 48 h. Em seguida, selecionavam-se as placas contendo entre 30 e 300 colônias. Nestas placas, era contado o número de colônias, o qual era muitiplicado pela recíproca da diluição correspondente, afim de se apresentar o resultado como número de bactérias por $\mathrm{ml}$ de suco.

Contagem de bactérias ácido-produtoras (segundo Sharf $3:$, 1972). Inoculou-se na superfície de ágar glicose-extrato de levedo-triptona adicionado de $0,04 \%$ de púrpura de bromocresol, $0,1 \mathrm{ml}$ de cada diluição decimal de suco. Em seguida, o inóculo era espalhado sobre a superficie do meio, com alça de Drigalsky esterilizada e as placas incubadas a $35^{\circ} \mathrm{C}$ por $3-5$ dias. Após a incubação, eram contadas as colônias que apresentavam forte reação ácida, em placas com 30 a 300 colônias e o resultado era referido como número de bactérias ácido-produtores por $\mathrm{ml}$ da amostra original.

Determinação do Número Mais Provável (NMP) de bactérias coliformes (segundo Thatcher e Clark ${ }^{34}$, 1973).

Prova Presuntiva: Inoculou-se, em triplicata, $1 \mathrm{ml}$ de cada diluição da amostra em três tubos contendo caldo lactosado com tubo de Durham, os quais eram incubados a $35^{\circ} \mathrm{C}$ por 24 e $48 \mathrm{~h}$. Após esse periodo, a presença de gás nos tubos de caldo lactosado indicava provas presuntivas positivas para bactérias do grupo coliforme.

Prova Confirmatória: Tranferia-se uma alçada de cultura de cada tubo com prova presuntiva positiva, para um tubo de caldo lactosado-bile-verde brilhante com tubo de Durham. Ao mesmo tempo, semeava-se uma alçada da cultura, em estrias, na superfície de ágar eosina azul de metileno, em placas. Os tubos e placas eram, a seguir, incubados a $35^{\circ} \mathrm{C}$ por $24 \mathrm{~h}$. Considerava-se a prova 
NASCIMENTO, D. do \& FURLANETTO, S.M.P. Determinação quantitativa de grupos de bactérias em sucos de laranja ao natural. Rev. Saúde públ., S. Paulo, 15:221-35, 1981.

confirmatória positiva quando havia produção de gás nos tubos de caldo lactosado-bile-verde brilhante $\mathrm{e} / \mathrm{ou}$ a presença de colônias negras ou claras com centro negro no ágar eosina azul de metileno.

Prova Completa: A partir de cada uma das placas de eosina azul de metileno positivas na prova confirmatória, isolava-se uma colônia com características das de coliformes e a mesma era semeada em dois tubos contendo respectivamente, caldo lactosado com tubo de Durham e ágar simples inclinado. Após incubação a $35^{\circ} \mathrm{C}$ por $24-48 \mathrm{~h}$, se o tubo de fermentação se revelasse com produção de gás, preparava-se a partir da cultura em àgar simples inclinado correspondente, um esfregaço em lâmina corado pelo método de Gram. A presença de bastonetes não esporulados e Gram-negativos, no ágar simples inclinado e a produção de gás no tubo de caldo lactosado correspondente constituia a prova completa positiva para bactérias do grupo coliforme. A partir do número de porções positivas da prova confirmatória, determinava-se o NMP de bactérias coliformes por $100 \mathrm{ml}$ da amostra original empregando-se, para tal, a tabela de Hoskins (American Public Health Association 1.2).

Determinaçäo do Número Mais Provável (NMP) de coliformes fecais (segundo Thatcher e Clark ${ }^{34}, 1973$ ). Após as leituras dos tubos de caldo lactosado da prova presuntiva para coliformes, transferia-se uma alçada de cultura do material de cada tubo positivo para um tubo correspondente de caldo EC, contendo tubo de Durham, procedendo-se a seguir a incubação em banho-maria a $44,5^{\circ} \mathrm{C}$ por 24 h. Após este periodo, a presença de gás indicava prova positiva para coliformes fecais. Em seguida, a partir do numero de tubos positivos, determinava-se o NMP dessas bactérias por $100 \mathrm{ml}$ de amostra, através da tabela de Números Mais Prováveis 1.2.
Determinação do Número Mais Provável (NMP) de estreptococos fecais (segundo Sharf 33, 1972). Na prova presuntiva, incoculou-se em triplicata, $1 \mathrm{ml}$ de cada diluição da amostra em três tubos de caldo dextrose-azida, os quais eram a seguir incubados a $35^{\circ} \mathrm{C}$ por $24-48$ h. Após a incubação, a presença de crescimento bacteriano indicava prova presuntiva positiva. De cada tubo positivo transferia-se uma alçada da cultura a um tubo de caldo etil violeta-azida, sendo os mesmos, a seguir, incubados a $35^{\circ} \mathrm{C}$ por 24 e $48 \mathrm{~h}$. Se houvesse crescimento bacteriano evidente com formação de um botão de cor violeta no fundo, considerava-se a prova confirmatória positiva do número de porções positivas das amostras e determinava-se o NMP empregando-se para isto a Tabela de Hoskins 1,2.

\section{RESULTADOS}

$\mathrm{Na}$ Tabela 1, encontram-se os resultados das determinaçōes feitas a partir de cada uma das 10 amostras de suco de laranja, colhidas em dias diferentes em dez lanchonetes ou restaurantes.

Na Tabela 2, constata-se que a contagem total de bactérias apresentou maior freqüência de resultados entre $10^{5}$ e $10^{6} \mathrm{mi}-$ crorganismos por $\mathrm{ml}$. Quanto à contagem de bactérias ácido-produtoras, embora em cinqüenta das amostras não tenhamos constatado seu crescimento, nas restantes positivas, os valores encontrados estavam com maior freqüência, também, entre $10^{5}$ e $10^{6}$ microrganismos por $\mathrm{ml}$.

$\mathrm{Na}$ Tabela 3 , pode-se verificar que em 76 amostras os NMP de estreptococos fecais foram de $10^{4}$ ou mais microrganismos por $100 \mathrm{ml}$. Para coliformes totais, 48 amostras revelaram-se com NMP de zero a $3 / 100 \mathrm{ml}$ enquanto para 52 esse valor era de 10 ou mais $/ 100 \mathrm{ml}$, sendo o resultado mais freqüente o compreendido entre $10 \mathrm{e}$ $10: 3 / 100 \mathrm{ml}$. Para coliformes fecais, 92 das 100 amostras examinadas revelaram-se com NMP de zero a $3 / 100 \mathrm{ml}$. 
NASCIMENTO, D. do \& FURLANETTO. S.M.P. Determinação quantitativa de grupos de bactérias em sucos de laranja ao natural. Rev. Saide públ., S. Paulo, 15:221-35, 1981.

T A B E L A 1

Número de microrganismos determinados para cada uma das 100 amostras de suco de laranja "ao natural" colhidas em dias diferentes, em 10 diferentes estabelecimentos.

\begin{tabular}{|c|c|c|c|c|c|}
\hline \multirow{3}{*}{$\begin{array}{c}\text { Amostra } \\
N^{\circ}\end{array}$} & \multicolumn{2}{|c|}{ Número de Microrganismos $/ \mathrm{ml}$} & \multicolumn{3}{|c|}{$\mathrm{NMP} / 100 \mathrm{ml}$} \\
\hline & \multirow{2}{*}{$\begin{array}{l}\text { Contagem } \\
\text { Total de } \\
\text { Bactérias } \\
\text { Mesófilas }\end{array}$} & \multirow{2}{*}{$\begin{array}{c}\text { Contagem } \\
\text { de Bactérias } \\
\text { Acido-Produtoras }\end{array}$} & \multicolumn{2}{|c|}{ Coliformes } & \multirow{2}{*}{$\begin{array}{c}\text { Estreptococos } \\
\text { Fecais }\end{array}$} \\
\hline & & & Totals & Fecais & \\
\hline 1 & 32.000 & 390.000 & 30 & $<3$ & 460.000 \\
\hline 2 & 369.000 & 850.000 & 160 & $<3$ & 1.200 .000 \\
\hline 3 & 510.000 & 558.000 & 30 & $<3$ & 240.000 \\
\hline 4 & 270.000 & 9.900 & $<3$ & $<3$ & 930.000 \\
\hline $\mathbf{5}$ & 49.000 & 17.500 & 94 & $<3$ & 190 \\
\hline 6 & 218.000 & 15.300 & $<3$ & $<3$ & 2.400 .000 \\
\hline 7 & 430.000 & $-{ }^{*}$ & 60 & $<3$ & 11.000 .000 \\
\hline 8 & 17.200 & - & $<3$ & $<3$ & 2.300 \\
\hline 9 & 990.000 & - & 90 & $<3$ & 43.000 \\
\hline 10 & 81.000 & - & $<3$ & $<3$ & 11.000 .000 \\
\hline 11 & 79.000 & 340.000 & $<3$ & $<3$ & 24.000 .000 \\
\hline 12 & 236.000 & 310.000 & $<3$ & $<3$ & 290.000 \\
\hline 13 & 360.000 & 1.200 & 62 & $<3$ & 230.000 \\
\hline 14 & 48.000 & 45.000 & 190 & $<3$ & 150.000 \\
\hline 15 & 240.000 & - & 200 & $<3$ & 150.000 \\
\hline 16 & 370 & - & $<3$ & $<3$ & 230 \\
\hline 17 & 35.000 & - & $<3$ & $<3$ & 43.000 \\
\hline 18 & 280.000 & - & $<3$ & $<3$ & 1.100 .000 \\
\hline 19 & 440.000 & - & $<3$ & $<3$ & 9.300 \\
\hline 20 & 35.000 & - & 94 & $<3$ & 43.000 \\
\hline 21 & 448.000 & 300 & 230 & $<3$ & 93.000 \\
\hline 22 & 790.000 & - & 30 & $<3$ & 73 \\
\hline 23 & 290.000 & 28.000 & 36 & $<3$ & $<3$ \\
\hline 24 & 71.000 & - & 91 & $<3$ & 750 \\
\hline 25 & 790.000 & - & $<3$ & $<3$ & 930 \\
\hline
\end{tabular}


NASCIMENTO, D. do \& FURLANETTO, S.M.P. Determinação quantitativa de grupos de bactérias em sucos de laranja ao natural, Rev. Saúde públ, S. Paulo, 15:221-35, 1981.

T A B E L A 1 (Continuação)

Número de microrganismos determinados para cada uma das 100 amostras de suco de laranja "ao natural" colhidas em dias diferentes, em 10 diferentes estabelecimentos.

\begin{tabular}{|c|c|c|c|c|c|}
\hline \multirow{3}{*}{$\begin{array}{c}\text { Amostra } \\
\mathrm{N}^{\circ}\end{array}$} & \multicolumn{2}{|c|}{ Número de Mierorganísmos $/ \mathrm{ml}$} & \multicolumn{3}{|c|}{$\mathrm{NMP} / 100 \mathrm{ml}$} \\
\hline & \multirow{2}{*}{$\begin{array}{l}\text { Contagem } \\
\text { Total de } \\
\text { Bactérias } \\
\text { Mesófilas }\end{array}$} & \multirow{2}{*}{$\begin{array}{c}\text { Contagem } \\
\text { de Bactérias } \\
\text { Acido-Produtoras }\end{array}$} & \multicolumn{2}{|c|}{ Coliformes } & \multirow{2}{*}{$\begin{array}{c}\text { Estreptococos } \\
\text { Fecais }\end{array}$} \\
\hline & & & Totais & Fecais & \\
\hline 26 & 2.700 .000 & - & $<3$ & $<3$ & 430.000 \\
\hline 27 & 22.500 & - & $<3$ & $<3$ & 73 \\
\hline 28 & 720.000 & 2.200 .000 & 92 & $<3$ & 4.600 .000 \\
\hline 29 & 161.000 & - & 930 & 230 & 73 \\
\hline 30 & 149.000 & - & 23.000 & 9.300 & 290 \\
\hline 31 & 760.000 & 1.420 .000 & $<3$ & $<3$ & $\geqslant 24.000 .000$ \\
\hline 32 & 160.000 & 2.200 .000 & 30 & $<3$ & 11.000 .000 \\
\hline 33 & 90.000 & 95.000 & 190 & $<3$ & 750.000 \\
\hline 34 & 280.000 & 1.300 .000 & 230 & $<3$ & 4.600 .000 \\
\hline 35 & 150.000 & 18.000 & 60 & $<3$ & 930.000 \\
\hline 36 & 160.000 & 120.000 & 30 & $<3$ & 930.000 \\
\hline 37 & 710.000 & - & 60 & 60 & 4.600 .000 \\
\hline 38 & 2.200 .000 & - & $<3$ & $<3$ & 430.000 \\
\hline 39 & 1.100 .000 & 1.020 .000 & $<3$ & $<3$ & $<3$ \\
\hline 40 & 2.200 .000 & - & 90 & $<3$ & 2.100 .000 \\
\hline 41 & 460.000 & 9.000 & $<3$ & $<3$ & 24.000 .000 \\
\hline 42 & 250.000 & 800.000 & 110 & $<3$ & 430.000 \\
\hline 43 & 50.000 & 130.000 & 290 & $<3$ & 930.000 \\
\hline 44 & 52.000 & 10.000 & 93.000 & $<3$ & 430.000 \\
\hline 45 & 2.070 .000 & 1.500 .000 & 30 & $<3$ & 2.100 .000 \\
\hline 46 & 15.700 & - & $<3$ & $<3$ & 23.000 \\
\hline 47 & 225.000 & - & 36 & $<3$ & 230.000 \\
\hline 48 & 190.000 & - & 30 & $<3$ & 1.500 .000 \\
\hline 49 & 300.000 & 6.100 .000 & 61 & $<3$ & $\geqslant 24.000 .000$ \\
\hline 50 & 340.000 & 340.000 & $<3$ & $<3$ & 2.000 \\
\hline
\end{tabular}


NASCIMENTO, D. do \& FURLANETTO, S.M.P. Determinaçāo quantitativa de grupos de bactérias em sucos de laranja ao natural. Rev. Sauide públ., S. Paulo, 15:221-35, 1981.

\section{T A B E L A 1 (Continuação)}

Número de microrganismos determinados para cada uma das 100 amostras de suco de laranja "ao natural" colhidas em dias diferentes, em 10 diferentes estabelecimentos.

\begin{tabular}{|c|c|c|c|c|c|}
\hline \multirow{3}{*}{$\begin{array}{c}\text { Amostra } \\
\mathrm{N}^{\circ}\end{array}$} & \multicolumn{2}{|c|}{ Número de Microrganismos $/ \mathrm{ml}$} & \multicolumn{3}{|c|}{$\mathrm{NMP} / 100 \mathrm{ml}$} \\
\hline & \multirow{2}{*}{$\begin{array}{l}\text { Contagem } \\
\text { Total de } \\
\text { Bactérias } \\
\text { Mesófilas }\end{array}$} & \multirow{2}{*}{$\begin{array}{c}\text { Contagem } \\
\text { de Bactérias } \\
\text { Ácido-Produtoras }\end{array}$} & \multicolumn{2}{|c|}{ Coliformes } & \multirow{2}{*}{$\begin{array}{c}\text { Estreptococos } \\
\text { Fecais }\end{array}$} \\
\hline & & & Totais & Fecais & \\
\hline 51 & 236.000 & 162.000 & 30 & $<3$ & 11.000 .000 \\
\hline 52 & 25.600 & 3.700 & $<3$ & $<3$ & 24.000 .000 \\
\hline 53 & 300.000 & 57.000 & $<3$ & $<3$ & 4.600 .000 \\
\hline 54 & 370.000 & 490.000 & $<3$ & $<3$ & 4.600 .000 \\
\hline 55 & 46.000 & 220.000 & $<3$ & $<3$ & 23.000 \\
\hline 56 & 10.000 .000 & - & $<3$ & $<3$ & 11.000 .000 \\
\hline 57 & 120.000 & - & 3.600 & 1.500 & 1.500 \\
\hline 58 & 164.000 & - & 94 & $<30$ & 75.000 \\
\hline 59 & 260.000 & 400.000 & 120 & $<3$ & 2.300 .000 \\
\hline 60 & 50.000 & 132.000 & $<3$ & $<3$ & 430.000 \\
\hline 61 & 2.830 & 380 & $<3$ & $<3$ & $<3$ \\
\hline 62 & 8.200 & - & $<3$ & $<3$ & 23.000 \\
\hline 63 & 57.000 & 1.580 .000 & 62 & $<3$ & 23.000 \\
\hline 64 & 3.800 & 100 & 61 & $<3$ & 7.500 \\
\hline 65 & 500 & 59 & $<3$ & $<3$ & $<3$ \\
\hline 66 & 300.000 & - & $<3$ & $<3$ & 4.600 .000 \\
\hline 67 & 100.000 & - & $<3$ & $<3$ & 15.000 \\
\hline 68 & 16.000 & - & 190 & $<3$ & 36 \\
\hline 69 & 13.000 & 8.000 & 1.200 & $<3$ & 240 \\
\hline 70 & 2.100 & - & $<3$ & $<3$ & 23.000 \\
\hline 71 & 216.000 & - & $<3$ & $<3$ & 23.000 \\
\hline 72 & 74.000 & 1.900 & $<3$ & $<3$ & 23.000 \\
\hline 73 & 223.000 & 300.000 & 360 & $<3$ & 15.000 \\
\hline 74 & 1.070 .000 & - & $<3$ & $<3$ & 930.000 \\
\hline 75 & 1.090 .000 & - & $<3$ & $<3$ & 4.300 \\
\hline
\end{tabular}


NASCIMENTO. D. do \& FURLANETTO. S.M.P. Determinação quantitativa de grupos de bactérias em sucos de laranja ao natural. Rer Saude públ., S. Paulo, 15:221-35. 1981.

T A B E L A 1 (Continuação)

Número de microrganismos determinados para cada uma das 100 amostras de suco de laranja "ao natural" colhidas em dias diferentes, em 10 diferentes estabelecimentos.

\begin{tabular}{|c|c|c|c|c|c|}
\hline \multirow{3}{*}{$\begin{array}{c}\text { Amostra } \\
\mathrm{N}^{\circ}\end{array}$} & \multicolumn{2}{|c|}{ Número de Microrganismos $/ \mathrm{ml}$} & \multicolumn{3}{|c|}{$\mathrm{NMP} / 100 \mathrm{ml}$} \\
\hline & \multirow{2}{*}{$\begin{array}{l}\text { Contagem } \\
\text { Total de } \\
\text { Bactérias } \\
\text { Mesófilas }\end{array}$} & \multirow{2}{*}{$\begin{array}{c}\text { Contagem } \\
\text { de Bactérias } \\
\text { Ácido-Produtoras }\end{array}$} & \multicolumn{2}{|c|}{ Coliformes } & \multirow{2}{*}{$\begin{array}{c}\text { Estreptococos } \\
\text { Fecais }\end{array}$} \\
\hline & & & Totais & Fecais & \\
\hline 76 & 9.000 & - & $<3$ & $<3$ & 4.300 \\
\hline 77 & 96.000 & - & 2.300 & $<3$ & 43.000 \\
\hline 78 & 598.000 & - & 36 & $<3$ & 43.000 \\
\hline 79 & 15.000 & - & 530 & $<3$ & 15.000 \\
\hline 80 & 208.000 & - & $<3$ & $<3$ & 93.000 \\
\hline 81 & 490.000 & 60.000 & 2.300 & 2.300 & 210.000 \\
\hline 82 & 120.000 & 600.000 & $<3$ & $<3$ & 4.600 .000 \\
\hline 83 & 800.000 & 1.000 .000 & $<3$ & $<3$ & 430.000 \\
\hline 84 & 470.000 & - & $<3$ & $<3$ & 23.000 \\
\hline 85 & 40.000 & - & $<3$ & $<3$ & $<3$ \\
\hline 86 & 740.000 & - & $<3$ & $<3$ & 23.000 \\
\hline 87 & 1.300 .000 & 900.000 & $<3$ & $<3$ & 430.000 \\
\hline 88 & 1.600 .000 & - & 30 & $<3$ & 360 \\
\hline 89 & 227.000 & 2.400 .000 & $<3$ & $<3$ & 43.000 \\
\hline 90 & 5.000 .000 & - & $<3$ & $<3$ & 1.500 .000 \\
\hline 91 & 30.000 & 1.200 .000 & 120 & $<3$ & 2.400 .000 \\
\hline 92 & 1.060 .000 & 12.900 .000 & 61 & $<3$ & 4.600 .000 \\
\hline 93 & 25.000 & 1.070 .000 & $<3$ & $<3$ & 430.000 \\
\hline 94 & 320.000 & - & $<3$ & $<3$ & 2.100 \\
\hline 95 & 74.000 & - & $<3$ & $<3$ & 430.000 \\
\hline 96 & 24.100 .000 & - & 190 & $<3$ & 430.000 \\
\hline 97 & 492.000 & - & 240.000 & $<3$ & 4.600 .000 \\
\hline 98 & 100.000 & - & 460.000 & $<30$ & 4.600 .000 \\
\hline 99 & 500.000 & - & 460.000 & 15.000 & 2.400 .000 \\
\hline 100 & 690.000 & 10.000 & 30 & $<3$ & $\geqslant 24.000 .000$ \\
\hline
\end{tabular}

* Ausência de Crescimento. 
NASCIMENTO, D. do \& FURLANETTO, S.M.P. Determinação quantitativa de grupos de bactérias em sucos de laranja ao natural. Rev. Saúde públ., S. Paulo, 15:221-35, 1981.

T A B E L A 2

Distribuição da contagem total de bactérias mesófilas e contagem de bactérias ácido-produtoras em 100 amostras colhidas em 10 diferentes estabelecimentos.

\begin{tabular}{|c|c|c|c|c|}
\hline \multirow{2}{*}{\multicolumn{3}{|c|}{$\begin{array}{l}\text { Número de } \\
\text { Microrganismos } / \mathrm{ml}\end{array}$}} & \multicolumn{2}{|c|}{ Número de Amostras } \\
\hline & & & \multirow{2}{*}{$\begin{array}{c}\text { Contagem } \\
\text { Total de } \\
\text { Bactérias } \\
\text { Mesófilas }\end{array}$} & $\begin{array}{c}\text { Contagem } \\
\text { de Batérias } \\
\text { Ácido-Produtas }\end{array}$ \\
\hline \multicolumn{3}{|c|}{0} & & 50 \\
\hline 1 & 1 & 10 & 0 & 0 \\
\hline 10 & - - & $10^{2}$ & 0 & 2 \\
\hline $10^{2}$ & - & $10^{3}$ & 2 & 2 \\
\hline $10^{3}$ & - - & $10^{4}$ & 5 & 8 \\
\hline $10^{4}$ & - & $10^{5}$ & 29 & 8 \\
\hline $10^{5}$ & - - & $10^{6}$ & 51 & 18 \\
\hline $10^{6}$ & - - & $10^{7}$ & 12 & 11 \\
\hline $10^{7}$ & - — & $10^{8}$ & 1 & 1 \\
\hline
\end{tabular}

$\mathrm{Na}$ Tabela 4, encontra-se a distribuição dos resultados das análises microbiológicas das dez amostras de suco de laranja ao natural, colhidas em dez domicilios, apenas como elementos de comparação entre as condiçōes microbiológicas dos sucos extraidos com os cuidados domésticos habituais com as daqueles coletados em casas comerciais.

\section{DISCUSSAO}

São de consenso geral os problemas de Saúde Pública acarretados pelos alimentos contaminados, bem como a preocupação de se eliminar os microrganismos patogênicos e não, obrigatoriamente, todos os microrganismos presentes nesses produtos. Deve ser salientado porém que, quando esses produtos são submetidos a exames microbiológicos na industria, geralmente os microrganismos patogênicos não são pesquisados dada a sua grande diversidade, 0 seu custo $e$ as dificuldades técnicas para a sua realização. Tais pesquisas são, no entanto, realizadas excepcionalmente quando $o$ alimento é suspeito de estar associado a um surto ou a casos de uma determinada doença. Assim, a análise microbiológica de alimentos baseia-se na determinaçăo, qualitativa ou quantitativa, de grupos de microrganismos denominados "indicadores", tais como as bactérias coliformes totais, coliformes fecais e estreptococos fecais $\$ .14,15,19$. 23,34 . 
NASCIMENTO, D. do \& FURLANETTO, S.M.P. Determinação quantitativa de grupos de bactérias em sucos de laranja ao natural. Rev. Saúde públ., S. Paulo, 15:221-35, 1981.

T A B E L A 3

Distribuição do NMP de coliformes totais, coliformes fecais e estreptococos fecais em 100 amostras colhidas em 10 diferentes estabelecimentos.

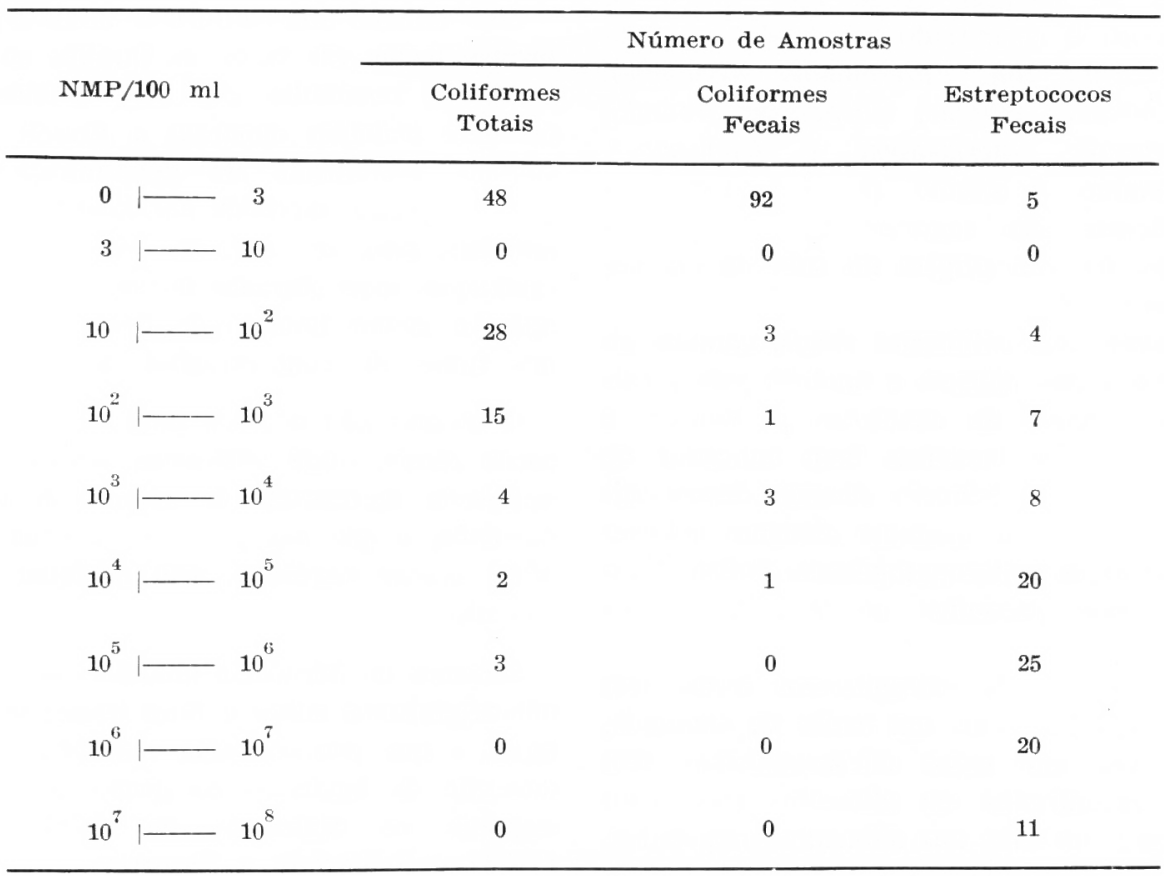

T A B E L A 4

Número de microrganismos determinados para cada uma das 10 amostras de suco de laranja "ao natural" colhidas em dias diferentes e diferentes residências sob os cuidados higiênicos usuais.

\begin{tabular}{|c|c|c|c|c|c|}
\hline \multicolumn{3}{|c|}{ Número de Bactérias } & \multicolumn{3}{|c|}{$\mathrm{NMP} / 100 \mathrm{ml}$} \\
\hline \multirow{2}{*}{$\begin{array}{c}\text { Amostra } \\
\qquad \mathrm{N}^{0}\end{array}$} & \multirow{2}{*}{$\begin{array}{l}\text { Contagem } \\
\text { Total de } \\
\text { Mesófilas }\end{array}$} & \multirow{2}{*}{$\begin{array}{c}\text { Contagem de } \\
\text { Ácido-Produtoras }\end{array}$} & \multicolumn{2}{|c|}{ Coliformes } & \multirow{2}{*}{$\begin{array}{c}\text { Estreptococos } \\
\text { Fecais }\end{array}$} \\
\hline & & & Totais & Fecais & \\
\hline 1 & 280.000 & $-^{*}$ & 43.000 & $<3$ & $<3$ \\
\hline 2 & 123.000 & - & 23.000 & $<3$ & 210 \\
\hline 3 & 193 & 730 & $<3$ & $<3$ & $<3$ \\
\hline 4 & 7.000 & - & $<3$ & $<3$ & 200 \\
\hline 5 & 20.000 & - & 43.000 & $<3$ & 4.300 \\
\hline 6 & 2.000 & 10.000 & 90 & $<3$ & 200 \\
\hline 7 & 3.000 & - & $<3$ & $<3$ & 62 \\
\hline 8 & 1.200 & - & 43.000 & $<3$ & 190 \\
\hline 9 & 230.000 & 97.000 & $<3$ & $<3$ & 4.600 .000 \\
\hline 10 & 3.100 & 20.000 & 190 & $<3$ & 160 \\
\hline
\end{tabular}

* Ausencia de Crescimento. 
NASCIMENTO, D. do \& FURLANETTO, S.M.P. Determinação quantitativa de grupos de bactérias em sucos de laranja ao natural. Rev. Saúde públ., S. Paulo, 15:221-35, 1981.

As bactérias coliformes, de fácil cultivo, geralmente estão associadas a organismos patogênicos intestinais, sendo hons indicadores de poluição fecal. Este grupo de bactérias é constituído principalmente pela Escherichia coli, Enterobacter aerogenes, Enterobacter cloacae, Citrobacter freundii, Citrobacter intermedium e Klebsiella?. Entretanto, é sabido que nem todos os coliformes são seguramente fecais, pois podem ter sua origem no solo ou em vegetais $8.14,15$.

Quanto aos coliformes fecais, comuns ao homem e aos animais e também pouco exigentes quanto às condições de cultivo, é um grupo de bactérias bom indicador de poluição fecal. Número elevado desses microrganismos em qualquer alimento indicam que espécies enteropatogênicas podem também estar presentes no material examinado ${ }^{34}$.

A presença de estreptococos fecais tem sido sugerida como um índice de sanidade, uma vez que esses microrganismos têm sido encontrados em alimentos tais como na água, no leite, nos alimentos congelados, nos ovos, nos peixes e nos mariscos. Larkin e col.2 (1955) mostraram que é mais freqüente a presença de estreptococos fecais em alimentos congelados do que os coliformes ou $E$. coli.

Sabemos que os estreptococos fecais possuem maior resistência que os coliformes, às condições do meio ambiente e aos processos de conservação normalmente aplicados aos alimentos. Esta resistência é a razão de não se preferir tomar tais microrganismos como indicadores de contaminação fecal recente, já que podem sobreviver em condiçōes adversas. Tal fato significa que diminui a possivel relação com a presença de agentes patogênicos, que, em geral, possuem menor resistência. Mesmo que houvesse agentes patogênicos chegados ao alimento ao mesmo tempo que os estreptococos fecais possivelmente persistiriam por menos tempo que estes últimos.

Porém, um alto número de estreptococos fecais em alimentos pode indicar condições higiênicas duvidosas e possibilidade de multiplicação de microrganismos patogênicos.

Com relação aos coliformes totais e coliformes fecais em sucos de laranja ao natural, os resultados por nós obtidos no presente trabalho mostram a grande dificuldade encontrada na determinação do NMP daquelas bactérias nas amostras examinadas, uma vez que, nos tubos de concentrações mais elevadas do suco analisado, aparece menor número de germes do que nos tubos de concentrações mais baixas.

O mesmo não ocorreu para os estreptococos fecais, onde obtivemos sempre uma seyüência decrescente de número de tubos positivos, o que nos permitiu determinar o NMP dessas hactérias, sem qualquer dificuldade.

Sabemos da influência inibitória de vários microrganismos sobre a flora bacteriana da água, o que provoca uma restrição à boa detecção de bactérias do grupo coliforme, segundo os trabalhos de Waksman ${ }^{35}$ (1941) e Schiavone e Passerine ${ }^{32}$ (1957) Espécies de Pseudomonas, Sarcina, Micrococcus, Flavobacterium, Proteus, Bacillus, bolores e leveduras dificultam a detecção do grupo coliforme em água, segundo os trabalhos de Kligler $\div 1$ (1919) e Weawer e Boiter 36 (1952). Foi mostrado por Reitter e Seligmann 30 (1957) que, quando bactérias, não coliformes, são introduzidas em caldo lactosado, podem multiplicar-se mais rapidamente o que intensificaria a inibição de coliformes, ou então, simplesmente, os sobrepujariam na população.

Hutchison e col. ${ }^{20}$ (1943) detectaram poucos coliformes, quando uma suspensão de vários organismos, não coliformes, numa concentração de 10.000 a 20.000 germes $/ \mathrm{ml}$ foi adicionada a tubos de caldo lactosado simultaneamente com uma suspensão de Escherichia coli com 10 germes por ml.

Segundo McCabel e col. ${ }^{24}$ a qualidade bacteriológica da água de distribuiçăo de 969 redes de abastecimento público foi 
NASCIMENTO, D. do \& FURLANETTO. S.M.P. Determinação quantitativa de grupos de bactérias er sucos de laranja ao natural. Rer Sứde públ., S. Paulo, 15.221-35, 1981.

analisada com a finalidade de determinar a relação entre a contagem total de bactérias em placas e a detecçāo de coliformes totais e fecais. A análise feita mostrou que a deteção de coliformes totais e fecais nāo foi alterada com relaçāo aos niveis de contagem-padrão até 500 germes por $\mathrm{ml}$, porém a positividade diminuia quando a população de bactérias nāo coliformes excedia de 1.000 organismos $/ \mathrm{ml}$. Isto mostra também que bactérias não coliformes, presentes em grande número, afetam adversamente a deteção de bactérias coliformes.

Tais resultados não se coadunam com os dados por nós obtidos, mostrados nas Tabelas de 1 a 4 , nos quais se verifica nāo haver relação com a contagem total de bactérias mesófilas e a determinação do NMP de coliformes totais e fecais.

$\mathrm{Na}$ determinação do NMP de coliformes totais, nas cem amostras de suco de laranja natural, um fato despertou-nus a atenção: quando transferiamos uma amostra do conteúdo de cada tubo positivo de caldo lactosado (prova presuntiva) para um tubo de caldo lactose bile verde brilhante (prova confirmatória), o crescimento neste meio geralmente não ocorria nas diluiçóes menores, e sin nas diluiçōes maiores. $A$ isso chamaremos, para facilidade de redação, de "comportamento discutivel"

Das cem amostras analisadas, trinta $e$ uma comportaram-se dessa maneira, o que ¿ um numero alto, porém, se levarmos em consideração o número de amostras negativas (num total de 48 ) a percentagem de amostras que apresentaram un "comportamento discutivel" chega a ser da ordem de $59,6 \%$.

Esse "comportamento discutivel" poderia ter ocorrido devido ao fato de que, nas diluições maiores, os coliformes teriam condições de sobrepujar outros microrganismos com condições então de se desenvolver e se multiplicar.

No caso especifico do suco por nós analisado, é muito provável que tenha havido um acontecimento semelhante ao que já foi verificado com a água. A água é um meio nutriente pobre, enquanto o suco de laranja natural é rico em ácidos orgânicos, sais minerais e carboidratos, segundo estudos de Barreto Junior:, tornando-se um bom meio de cultura para microrganismos que porventura ai estejam presentes.

Os fatores que poderiam contribuir para uma alta contagem de microrganismos podem ser: a superficie externa do fruto, o equipamento usado (extrator) e o interior do fruto.

A superficie externa do fruto, como fator de contaminação, é bastante discutida, pois, segundo Faville e Hill ${ }^{\prime \prime}$ (1951), que pulverizaram a superficie externa da laranja com organismos indicadores, tais como, Escherichia coli e Serratia mascescens, não conseguiram isolar, posteriormente, do suco, estes germes, mesmo quando o suco de laranja pulverizada foi extraido sem uma lavagem prévia. Estes estudos estão em concordancia com o trabalho de Patrick". (1950) que concluiu que o uso de laranjas com superficic limpa não garante a obtençāu de um suco com baixa contagem de microrganismos.

Porém, segundo Beisel 4 (1951), existe uma relação direta entre o grau de contaminação da superfície da laranja e a quantidade de microrganismos encontrada no suco.

Quanto à presença de coliformes na superficie da laranị, também é assunto conflitante, pois alguns trabalhos realizados por Beisel e Troy: (1949), Dack" (1959) e Wolford (1956) evidencian a presença de coliformes, ao contrário de Patrick (1951) que não conseguiu resultados positivos. Wolford e Berry ${ }^{4 \prime}$ (1948), Wolford (1956) e Dack" (1955) chegaram a sugerir que os coliformes fizessem parte da flora normal da laranja.

Testes laboratoriais têm mostrado que bactérias coliformes, às vêzes, estão presentes no suco de laranja que sofreram 
NASCIMENTO, D. do \& FURLANETTO. S.M.P. Determinação quantitativa de grupos de bactérias em sucos de laranja ao natural, Rev. Saúde públ., S. Paulo, 15:221-35, 1981.

rigorosos cuidados na colheita e que foram lavadas com substâncias desinfetantes, antes da extração do suco, conforme estudos de Dack ${ }^{\circ}$ (1955) e Beisel e Troy ‘ (1949).

No estudo feito por Hill e Faville ${ }^{17}$ (1951) ficou mostrado que os microrganismos são capazes de crescer no interior da laranja, se puderem aí penetrar. Os organismos, depois de inoculados artificialmente na laranja, quando ainda na árvore, produzem uma contagem máxima de microrganismos dentro de, aproximadamente, três semanas. Esta contagem foi mantida durante o periodo de cinco semanas de observação.

Alguns estudos realizados por Dack * (1955) e Beisel e Troy" (1949) mostraram que bactérias coliformes estão presentes frequientemente na laranja, mesmo antes desta ser colhida. Em sucos preparados com Iaranjas "passadas" foram encontradas duas mil e quinhentas vêzes mais organismos do que naqueles preparados da mesma maneira, com laranjas sadias, segundo os estudos de Wolford e Berry 40 (1948).

Ampla variação na contagem de microrganismos pode ser observada a partir de sucos de frutos aparentemente sadios, porém a eliminação dos frutos não sadios pode diminuir, significantemente, a carga microbiológica do suco extraído $6,16,26,40$.

$\mathrm{Na}$ Tabela 4 encontra-se os resultados das análises microbiológicas de dez amostras de suco de laranja ao natural, colhidas em dez domicilios. As análises desse material foram realizadas apenas para termos uma comparação entre as condições microbiológicas de sucos de laranja extraidos com os cuidados domésticos habituais e os resultados obtidos a partir das amostras coletadas em restaurantes e lanchonetes.

Pode-se verificar, analisando os resultados apresentados na Tabela 4 e comparando-os com os da Tabela 1, que foi examinado um pequeno número de amostras de suco de laranja obtidos em domicilios; as suas condições microbiológicas foram, de forma geral, melhores que as observadas para os sucos colhidos em restaurantes e lanchonetes universitários.

Observando as Tabelas 2 e 3 podemos notar onde houve maior frequiência na distribuição dos grupos de microrganismos. A contagem padrão de bactérias mesófilas apresentou maior freqüuencia de resultados entre $10^{5}$ e $10^{\text {s }}$ microrganismos por $\mathrm{ml}$; o NMP de estreptococos fecais é mais freqüente entre $10^{5}$ e $10^{\circ}$ microrganismos por $100 \mathrm{ml}$. $\mathrm{Na}$ contagem de bactérias ácido-produtoras, cinquienta das cem amostras analisadas resultaram negativas. Para as cinqüenta restantes positivas, os valores encontrados estavam, com maior freqüência, entre $10^{3}$ e $10^{6}$ microrganismos por ml.

Em nosso país, quanto aos padrões legais para sucos de frutas, encontramos referências apenas com relação a coliformes totais e fecais. Assim, a Portaria no 410 de 27/9/74 do Ministério da Agricultura 25 exige, como padrão para suco simples (natural) não congelado, a ausência de organismos coliformes em 5 porçōes de $10 \mathrm{ml}$ e ausência de microrganismos patogênicos.

Em 1978, dois novos padrões para sucos de frutas foram estabelecidos. Um a nivel nacional, do Ministério da Saúde 31 e 0 outro para o Estado de São Paulo 10. No primeiro caso, para refrescos, sucos e nectares, a Resolução da Comissão Nacional de Normas e Padrões para Alimentos (CNNPA) do Ministério da Saúde admite para bactérias do grupo coliforme de origem fecal, um máximo de $10 / \mathrm{ml}$, nada constando a respeito de outros microrganismos. Para - Estado de São Paulo, de acordo com os padrões estabelecidos pela Secretaria da Saúde ${ }^{10}$, as características microbiológicas para sucos integrais de frutas deverão obedecer ao seguinte padrăo: bactérias coliformes: máximo $100 / \mathrm{ml}$; bactérias do grupo coliforme de origem fecal: ausência em $1 \mathrm{ml}$.

No presente estudo, embora seguindo uma metodologia diferente da exigida pela Por- 
NASCIMENTO, D. do \& FURLANETTO, S.M.P. Determinaçăo quantitativa de grupos de bactérias em sucos de laranja ao natural. Rev. Saride puibl., S. Paulo, 15:221-35, 1981.

taria n 410 de $27 / 9 / 74$, do Ministério da Agricultura ${ }^{25}$, obteve-se maior freqüência de amostras revelando-se com um NMP de coliformes totais por $100 \mathrm{ml}$ menor que 3, embora tenha sido constatada a ocorrência de $24 \%$ das amostras com valores de $10^{2}$ ou mais/100 ml. Com relação aos coliformes fecais, $92 \%$ das amostras apresentou-se com NMP igual ou inferior a 3 por $100 \mathrm{ml}$. Estes resultados estão em concordância com us obtidos por Nolte e Von Loesecke 27 (1940), Garcia ${ }^{13}$ (1944) e Wolford ${ }^{37}$ (1950) que isolaram organismos coliformes do suco de laranja. Entretanto, estão em desacordo com o verificado por Ferraro e Appleman 1: (1956) e Patrick $28,29(1950,1951)$, os quais não conseguiram isolar coliformes en suco de laranja.

É também de grande importância manter 0 equipamento de extração do suco, em boas condiçóes sanitárias $11,16,26,40$, uma vez que microrganismos podem nele multiplicar-se.

Como verificamos em nosso trabalho, a contaminação dos sucos de Jaranjas obtidos em restaurantes e lanchonetes, parece ser mais elevada do que aquela apresentada em amostras provindas de residências $e$ obtidas com os cuidados domésticos normais de higiene. Tais contaminações dizem respeito ao número total de germes e são evidentes na contagem de bactérias ácido-produtoras.

Queremos crer que a falta de limpeza imediata dos equipamentos extratores, bem como a exposição do suco a temperatura ambiente por um tempo prolongado, em restaurantes e lanchonetes, pernitem a multiplicação de uma grande gama de microrganismos.

Por outro lado, muitos autores $7.18,27,28,3 \times$, afirmam que a aparente limpeza do extrator não está relacionada com a variação na contagem de germes do suco de laranja.

A qualidade do fruto (o interior do fruto) parece ser realmente 0 fator mais importante da contaminação e a maioria dos trabalhos na literatura, são a favor desta assertiva $7,18,27,28,38$.

\section{CONCLUSOES}

Pelos resultados obtidos através da análise microbiológica de suco de laranja ao natural, colhido em lanchonetes e restaurantes universitários, parece-nos lícito concluir que:

1) A contagem padrão de bactérias mesófilas apresentou maior frequêencia de resultados entre $10^{5}$ e $10^{\circ}$ microrganismos por $\mathrm{ml}$.

2) $\mathrm{Na}$ contagem de bactérias ácido-produtoras, 50 das 100 amostras analisadas não apresentaram crescimento. Para as 50 amostras restantes positivas, os valores encontrados com maior freqüência estão entre $10^{5}$ e $10^{6}$ microrganismos por $\mathrm{ml}$.

3) $\mathrm{Na}$ determinação do NMP de coliformes totais 48 das 100 amostras analisadas apresentaram valores menores que 3 por $100 \mathrm{ml}$ sendo que na determinação do NMP de coliformes fecais 92 amostras apresentaram valores também menores que 3 por $100 \mathrm{ml}$.

NASCIMENTO, D. do \& FURLANETTO, S.M.P. LQuantitative determination of bacteria groups in fresh, natural orange juice]. Rev. Saúde pủbl., S. Paulo, 15:221-35, 1981.

ABSTRACT: This investigation was carried out to discover the aerobic microbiota in natural orange juice served the public. Counts were made of mesophilic bacteria and acid producers, and the most probable number of totally coliform bacteria, fecal bacteria, and fecal streptocci was determined.

UNITERMS: Food microbiology. Juices. Orange juice. 
NASCIMENTO, D. do \& FURLANETTO, S.M.P. Determinação quantitativa de grupos de bactérias em sucos de laranja ao natural. Rev. Saúde públ., S. Paulo, 15:221-35, 1981.

\section{REFERENCIAS BIBLIOGRAFICAS}

1. AMERICAN PUBLIC HEALTH ASSOCIATION. Standard methods for the examination of water and wastewater. 12th ed. New York, 1965.

2. AMERICAN PUBLIC HEALTH ASSOCIATION. Standard methods for the examination of water and wastewater. 14th ed. Washington, 1975.

3. BARRETO JUNIOR, A. Studies on the rate of growth of potential spoilage bacteria in orange juice. Florida, University of Florida, 1953. [Thesis - University of Florida]

4. BEISEL, C. G. Controling contamination in a citrus canning plant. Canner, Chicago, $109: 16-8$, 1951.

5. BEISEL, C. G. \& TROY, V. S. The Vaughn-Levine boric acid medium as a screening presumptive test in the examination of frozen concentrated orange juice. Fruti Prod. J., Chicago, 28:356-7, 1949.

6. BERRY, J. M. et al. Growth characteristics of spoilage organisms in orange juice and concentrate. Food Technol., 10:553-6. 1956.

7. BROKAW. C. $\mathrm{H}$. The role sanitation in quality control frozen citrus concentrates. Food Technol., 6:344-9, 1952.

8. Christováo. D. de A. Padrōes bacteriológicos. In: Agua. qualidade. padrões de potabilidade e poluição. São Paulo. CETESB, 1974. p. 57-119.

9. DACK, G. M. Significance of enteric bacilli in foods. Amer. J. publ. Hith, 45: 1151-6, 1955 .

10. DECRETO no 12.342 - 27 de setembro de 1978. São Paulo, Secretaria da Saúde. 1979.

11. FAVILLE, L. W. \& HILL. E. C. Incidence and significance of microorganisms in citrus juices. Food Technol., 5:423-5. 1951.

12. FERRARO, F. M. \& APPLEMAN. M. D Microbiology of frozen orange concentrate. IV. Further studies of enterococci in frozen orange concentrate. Bact. Proc. $9: 27,1956$

13. GARCIA apud TANNER, F. W. Microbiology of foods. Champaign, Garrard Pres, 1944.
14. GELDREICH, E. E. Fecal coliform concepts in stream pollution. Wat. Sew. Wks, 114, 1967. [separata]

15. GELDREICH, E. E. Qualidade microbiológica em águas potáveis. In: Desinfecção de águas. São Paulo, CETESB, 1971. p. $73-93$.

16. HAYS, G, L. \& RIESTER, D. W, The control of off-odor spoilage in frozen concentrated orange juice. Food Technol., 6:386-9, 1952 .

17. HILL, E. C. \& FAVILLE, L. W. Studies on the artificial infection of orange with acid-tolerant bacteria. Proc. Fla. St. hort. Soc., Lake Alfred, 64:174-7. 1951.

18. HUCKER, G. J. et al. The source of bacteria in processing and their significance in frozen vegetables. Food Technol, $6: 147-55,1952$.

19. HUNTER, A. C. Uses and limitation of the coliform group in sanitary control of food production. Food Res., 4:531-8, 1939 .

20. HUTCHISON, D. et al. The incidence and significance of microorganisms antagonistic to Escherichia coli in water. $J$. Buct., $45: 29,1943$.

21. LIGLER, I. J. Non-lactose fermenting bacteria from polluted wells and sub-soil, J. Bact., 4:35-42. 1919.

22. LARKIN. E. P. et al. Fecal streptococcl in frozen foods. I. A bacteriological survey of some commercially frozen foods. Appl. Microbiol., 3:98-101. 1955.

23. LEITÃo. M. F. de F, et al. Coliformes totais e fecais como indicadoles de contaminação II - Avaliação do teste para caracterização de coliformes fecais Bol. Inst. Tecnol. Alim., 4:13-21. 1971, 1972.

24. McCABEL. L. J. et al. Survey of community water supply systems. J. Amer. Water Wks Ass, 62:670. 1970.

25. MINISTÉRIO DA AGRICULTURA. Portaria no 410 de 27 de setembro de 1974 . Diário Oficial, Brasilia, 8 out. 1974. Supl. esp., p. 11495. 
NASCIMENTO, D. do \& FURLANETTO, S.M.P. Determinação quantitativa de grupos de bactérias em sucos de laranja ao natural. Rev. Saúde públ., S. Paulo, 15:221-35, 1981.

26. MURDOCK, D. I. et al. Some observations of aum-forming organisms found on fruit surfaces. Proc. Fla. St. hort. Soc., Lake Alfred, 66:278-81, 1953.

27. NOLTE, A. J. \& VON LOESECHE, H. W. Types of organism surving in commercially pasteurized citrus juices in Flo. rida. Food Res., 5:73-81, 1940.

28. PATRICK, R. Microbiological surveys of citrus processing plants auring the 1948- 1949 season. New Orleans. Louisiana. Southern Regional Research Laboratory. 1950.

29. PATRICK, R. Sources of coliform bacteria in citrus juice for concentrates. Proc. Fla. St. hort. Soc., Lake Alfred. 64:178-81, 1951.

30. REITter, R. \& SELIGMANN, R. Pseudomonas aeruginosa in drinking water. $J$. appl. Bact., 20:45, 1957.

31. RESOLUÇÃO ne $13 / 78$ da Comissão Nacional de Normas e Padrões para Alimentos. Didrio Oficial, Brasilia, 25 jul. 1978. Supl. esp., p. 11616.

32. SCHIAVONE, E. L. \& PASSERINE, L. M. D. - El genero Pseudomonas aeruginosa en la determinacion de la potabilidad del agua de bebida. Sem. med, Buenos Aires, 111:1151-7, 1957.

33. SHARF, J. M. Exame microbiológico de alimentos. $2^{\mathrm{a}}$ ed. São Paulo. Polígono. 1972.
34. THATCHER, F. S. \& CLARK, D. S. Andlisis microbiologico de los alimentos. Zaragoza, Acribia, 1973.

35. WAKSMAN, S. A. Antagonistic relations on microorganisms. Bact. Rev., 5:231-91, 1941 .

36. WEAWER, R. H. \& BOITER, T. Antibiotic-producing species of Bacillus form well water. Trans. Ky. Acad. Sci. Lexington, $13: 183,1952$.

37. WOLFORD, E. R, Bacteriological studies of frozen orange juice stored at $10 \mathrm{~F}$. Food Technol, 4:241-5. 1950.

38. WOLFORD, E. R. Certain aspects of the microbiology of frozen concentrated orange juice. Amer. J. publ. Hlth, 46:708-15, 1956.

39. WOLFORD, E. R. A source of coliform in frozen concentrated orange juice. Fruit surface contamination. Appl. Microbiol., 4:250-3, 1956.

40. WOLFORD. E. R. \& BERRY. J. A. Condition of oranges as affecting bacterial of frozen juices with emphasis on coliform organisms. Food Res.; 13:172-8, 1948.

Recebido para publicação em 29/10/1980 Aprovado para publicação em 08/12/1980 